\title{
Electrochemical Determination of Dopamine Based on Carbon Nanotube-Sol-Gel Titania-Nafion Composite Film Modified Electrode ${ }^{\dagger}$
}

\author{
Ji Ae Park, Byung Kun Kim, Han Nim Choi, ${ }^{*}$ and Won-Yong Lee ${ }^{*}$ \\ Department of Chemistry and Center for Bioactive Molecular Hybrids, Yonsei University, Seoul 120-749, Korea \\ "E-mail:forhanmin@gmail.com (H.N.Choi),wylee@yonsei.ac.kr (W.-Y. Lee) \\ Received August 9, 2010, Accepted September 8, 2010
}

\begin{abstract}
A highly sensitive electrochemical detection method for dopamine (DA) has been developed by relying on a multiwalled carbon nanotube (CNT)-sol-gel titania-Nafion composite film modified glassy carbon (GC) electrode. The CNT-titania-Nafion/GC electrode exhibited excellent electrocatalytic activity towards DA. Therefore, the CNT-titaniaNafion/GC electrode showed improved voltammetric and amperometric responses for DA compared to those obtained with both titania-Nafion/GC and Nafion/GC electrodes. The CNT-titania-Nafion/GC electrode gave a linear response $\left(\mathrm{R}^{2}=0.999\right)$ for DA from $0.5 \mu \mathrm{M}$ to $0.5 \mathrm{mM}$ with a detection limit $(\mathrm{S} / \mathrm{N}=3)$ of $0.1 \mu \mathrm{M}$ and a good sensitivity of 150 $\mathrm{mA} / \mathrm{M}$ while other electrodes such as CNT-Nafion/GC, titania-Nafion/GC, and a bare GC gave a sensitivity of 89 , 39 , and $36 \mathrm{~mA} / \mathrm{M}$, respectively. Besides, the CNT-titania-Nafion/GC electrode displayed very fast response time within $2 \mathrm{~s}$. The modified electrode showed good selectivity against ascorbic acid. The modified electrode showed good stability and reproducibility. The CNT-titania-Nafion/GC electrode was applied to the determination of DA in urine and serum samples.
\end{abstract}

Key Words: Dopamine, Sol-gel technique, Titania-Nafion composite film, Carbon nanotubes

\section{Introduction}

Dopamine (DA) is one of the most significant neurotransmitter and plays an important role in the central nervous, renal, hormonal, and cardiovascular systems. Abnormal DA level may results in some serious diseases such as Parkinson's disease and schizophrenia. ${ }^{1}$ Therefore, the detection of DA in biological samples is very important. As well known, the major difficulty in the electrochemical DA detection is the interference effect from ascorbic acid (AA), which exists about $100-1000$ times higher concentration than DA which is sub $\mu \mathrm{M}$ concentration in the extracellular fluid of the central nervous system. Moreover, DA and AA have similar anodic peak potentials at almost all electrode materials, which result in overlapped voltammetric responses. ${ }^{2,3}$ Besides, the oxidized DA mediates the electrochemical oxidation of AA, and the electrode surface can be easily fouled by the product of AA oxidation. ${ }^{4}$ In order to solve these problems and to enhance the selectivity and sensitivity, many approaches have been studied over the past several decades. ${ }^{2-21}$ These include pretreatment and modification of electrode surface with various materials such as self-assembled monolayers, ${ }^{4,5}$ permselective film coatings such as Nafion ${ }^{6}$ and electropolymerized polymer, ${ }^{7}$ zeolite, ${ }^{2}$ cyclodextrins, ${ }^{8}$ and DNA. ${ }^{9}$

Because of the excellent electrocatalytic activity of noble metal nanoparticles (NPs), ${ }^{11-14}$ carbon based nano-materials such as nanofiber, ${ }^{15}$ graphene, ${ }^{17}$ and nanotube, ${ }^{10,18-20}$ the DA sensors based on these nano-materials exhibited good sensitivity and stability. Despite of these great advantages of those carbonbased nano-materials, the insolubility of them, especially carbon nanotube (CNT), in most solvents is one of the most difficult obstacles for their wide application in electrochemical sensors.

\footnotetext{
${ }^{\top}$ This paper is dedicated to Professor Hasuck Kim for his outstanding contribution to electrochemistry and analytical chemistry.
}

Previously, we reported that the incorporation of Nafion in the sol-gel derived titania film results in greater pore size $(3.14 \mathrm{~nm})$ than that of the pure Nafion film $(2.82 \mathrm{~nm})$, thus leading to faster diffusion of analyte into the film and also leading to the increased charge transport. ${ }^{22}$ In addition, the titania-Nafion composite has the ability to disperse the CNT. ${ }^{23}$ Therefore, the CNT-doped titania-Nafion mesoporous composite has been advantageously used for the fabrication of phenol, ${ }^{24}$ alcohol ${ }^{25}$ and glucose ${ }^{26}$ biosensors. The biosensors based on the CNT-titania-Nafion composite film exhibited substantial improvement in long-term stability because of the mechanical stability as well as biocompatibility of the composite film. Therefore, the present CNTtitania-Nafion composite can combine the advantages of CNT with those of the titania-Nafion composite, and thus can be used for the fabrication of CNT-based electrochemical sensors and biosensors. In this paper, we describe the characteristics of the CNT-titania-Nafion/GC electrode for the electrochemical detection of DA by cyclic voltammetry (CV), amperometry, and square-wave voltammetry (SWV). The attractive performance of the CNT-based DA sensor was evaluated over other reported DA sensors. The CNT-titania-Nafion/GC electrode was applied to the determination of DA in urine and serum samples. The proposed method showed good recovery and reproducibility.

\section{Experimental}

Reagents. Titanium(IV) isopropoxide (Ti(OR) $)_{4}(\mathrm{R}=\mathrm{CH}$ $\left.\left(\mathrm{CH}_{3}\right)_{2}, 99.999 \%\right)$ ), Nafion ${ }^{\circledR}$ (perfluonated ion-exchange resin solution, $5 \mathrm{wt} \%$ in mixture of lower aliphatic alcohols and water), 3-hydroxytyramine hydrochloride (dopamine, 98\%) and L-ascorbic acid (AA, 99+\%) and uric acid (UA) were purchased from Aldrich Chemical Co. (Milwaukee, WI, USA). Multiwalled CNT (95\% purity, diameter: $30 \pm 15 \mathrm{~nm}$, and length: 5 $20 \mu \mathrm{m})$ was obtained from NanoLab (Newton, MA, USA). 
Water for all solutions was purified using a Milli-Q water purification system (Millipore, Bedford, MA, USA). Unless otherwise noted, all chemicals were reagent grade and were used without further purification.

Instrumentation. All electrochemical experiments were performed with an EG\&G PAR 273A potentiostat/galvanostat (EG\&G Princeton Applied Research, Princeton, NJ, USA) with a conventional three-electrode system in a $15 \mathrm{~mL}$ electrochemical cell. Electrochemical impedance experiments were performed with EG\&G 273A potentiostat (Oak Ridge, TN, USA) and Frequency response detector model 1025 (Oak Ridge, TN, USA). The working electrode was GC electrode $\left(0.07 \mathrm{~cm}^{2}\right.$, Bioanalytical Systems Inc.) coated with the composite films, and a platinum wire as the counter electrode. All the potentials quoted here were relative to an $\mathrm{Ag} / \mathrm{AgCl}(3 \mathrm{M} \mathrm{NaCl})$ reference electrode.

Preparation of CNT-titania-Nafion/GC electrode. The titania $\left(\mathrm{TiO}_{2}\right)$ sol was prepared by the hydrolysis and condensation by mixing $1 \mathrm{~mL}$ of $0.15 \mathrm{M} \mathrm{Ti}\left(\mathrm{OC}_{4} \mathrm{H}_{9}\right)_{4}$ dissolved in propan-2-ol and $3 \mathrm{~mL}$ of deionized water and followed by $7 \mu \mathrm{L}$ of $0.1 \mathrm{M} \mathrm{HCl}$ solution under vigorous stirring for at least $1 \mathrm{~h}$ similar to the previous report. $^{22}$ The titania sol was mixed with diluted Nafion $(\mathrm{EtOH}:$ Nafion $=4: 1, \mathrm{v} / \mathrm{v})$ to form the titania-Nafion composite solution $(1: 1, \mathrm{v} / \mathrm{v})$. A $1.0 \mathrm{mg}$ CNT was dispersed in $1.0 \mathrm{~mL}$ titania-Nafion composite solution, and the mixture was agitated in an ultrasonic bath for $90 \mathrm{~min}$, giving a black dispersion.

GC electrode was polished before each experiment with 0.05 $\mu \mathrm{m} \gamma$-alumina powder, rinsed thoroughly with distilled water. An aliquot of $2 \mu \mathrm{L}$ CNT-doped composite solution was handcast on the surface of a pre-cleaned GC electrode. The thin composite films were dried for $10 \mathrm{~min}$ at room temperature and the modified electrode was stored in $0.05 \mathrm{M}$ phosphate buffer at pH 7.0 for $30 \mathrm{~min}$ in order to swell the composite modified GC electrode. When not in use, the electrode was stored in $0.05 \mathrm{M}$ phosphate buffer at $\mathrm{pH} 7.0$.

Experimental conditions. Cyclic voltammetric experiments employed at a scan rate of $50 \mathrm{mV} / \mathrm{s}$ in the scan range of $-0.3 \sim$ $+0.8 \mathrm{~V}$. SWV was used for the determination of DA in the presence of AA. SWV conditions were $25 \mathrm{mV}$ pulse height, $10 \mathrm{mV}$ step height, $20 \mathrm{~Hz}$ frequency and $100 \mathrm{mV} / \mathrm{s}$ scan rate. Amperometric experiments were carried out in an electrochemical cell containing $10 \mathrm{~mL}$ of $0.05 \mathrm{M}$ phosphate buffer at $\mathrm{pH} 7.0$ under constant stirring. A magnetic stirrer (600 rpm) and a stirring bar provided the convective transport in the amperometric experiments. A working potential of $+0.4 \mathrm{~V} v s . \mathrm{Ag} / \mathrm{AgCl}(3 \mathrm{M} \mathrm{NaCl})$ was applied to the working electrode and the background current was allowed to decay to a steady state before aliquots of standard solutions of DA were added to the electrochemical cell. All experiments were performed at room temperature.

Electrochemical impedance measurement. A conventional three-electrode system was employed with a platinum wire as counter electrode, glassy carbon $\left(0.07 \mathrm{~cm}^{2}\right)$ electrode coated with the prepared composite films as a working electrode, and an $\mathrm{Ag} / \mathrm{AgCl}(3 \mathrm{M} \mathrm{NaCl})$ reference electrode. The $\mathrm{AC}$ impedance spectra were recorded in $5.0 \mathrm{mM} \mathrm{K}_{3} \mathrm{Fe}(\mathrm{CN})_{6}$ and $\left.\mathrm{K}_{4} \mathrm{Fe}(\mathrm{CN})_{6}\right)$ $(1: 1, \mathrm{v} / \mathrm{v})$ solution in $0.05 \mathrm{M}$ phosphate buffer $(\mathrm{pH} 7)$. The spectra were obtained in the frequency range from $100 \mathrm{mHz}$ to $100 \mathrm{kHz}$ at a bias potential of $0.0 \mathrm{~V}$ with alternating voltage of
$5.0 \mathrm{mV}$. The impedance spectra were plotted in the form of impedance plane plot (Nyquist plots).

\section{Results and Discussion}

Electrochemical behavior of CNT-titania-Nafion/GC electrode. Figure 1 shows cyclic voltammograms of DA at bare GC and different modified GC electrodes in $0.05 \mathrm{M}$ phosphate buffer ( $\mathrm{pH}$ 7.0). The voltammetric behavior of DA at the bare GC electrode showed almost irreversible electrode reaction with sluggish and small responses at $+0.34 \mathrm{~V}$ for the oxidation process and $+0.06 \mathrm{~V}$ for the reduction process. The titania-Nafion composite modified GC electrode also exhibited irreversible DA voltammetric behavior with even larger peak separation $\left(\Delta \mathrm{E}_{\mathrm{p}}=0.42 \mathrm{~V}\right)$ than at the bare GC electrode $\left(\Delta \mathrm{E}_{\mathrm{p}}=0.28 \mathrm{~V}\right)$ because of the mass transport barrier of the titania-Nafion composite film on the GC electrode surface. However, the anodic current for DA increased almost twice because the DA exists as a cation in $0.05 \mathrm{M}$ phosphate buffer ( $\mathrm{pH} 7.0$ ), which can be sensitively detected at the negatively charged titania-Nafion composite modified GC electrode via electrostatic interaction. The CNT-titania-Nafion/GC electrode exhibited less positive oxidation potential at $+0.29 \mathrm{~V}$ and less negative reduction potential at $+0.07 \mathrm{~V}$, and the anodic current for DA obviously increased 2.5-fold and 1.4-fold larger than those obtained at a bare GC and titania-Nafion/GC electrode, respectively. The result indicates that CNT has obvious catalytic effect towards the oxidation of DA as reported previously in the literature ${ }^{10}$ and the titania-Nafion composite is a good matrix for the fabrication of the CNT-based electrochemical sensors. ${ }^{23}$ When the CNT is doped only in Nafion, the CNT-Nafion/GC electrode exhibited $40 \%$ smaller anodic current for DA than that at the CNT-titaniaNafion/GC electrode, and even 17\% smaller than at the titaniaNafion/GC electrode. The result indicates that the titania-Nafion composite is much more effective matrix than the pure Nafion for the construction of CNT-based electrochemical sensors. The larger anodic current for DA at the CNT-titania-Nafion/GC electrode than at the CNT-Nafion/GC electrode in the present

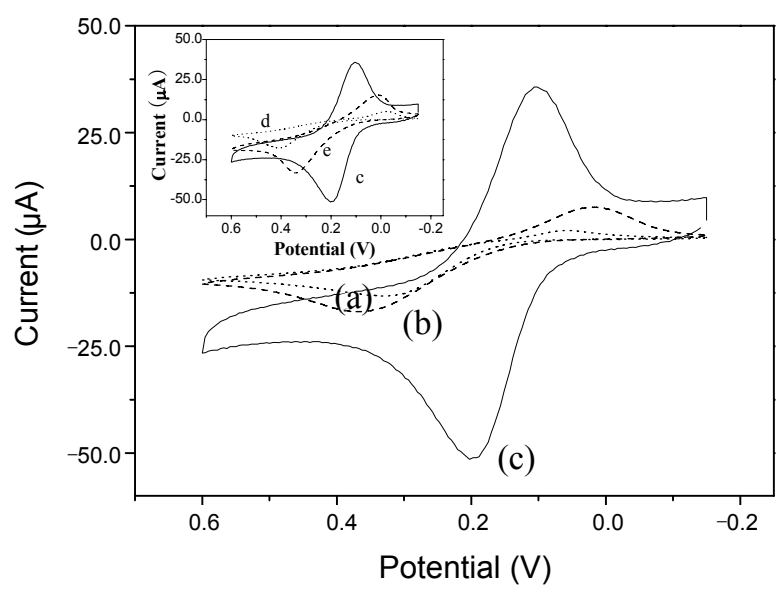

Figure 1. Cyclic voltammograms of 1.0 mM DA at bare GC (a), titaniaNafion/GC (b) and CNT-tatania-Nafion/GC (c) electrodes. Inset: CVs of 1.0 mM DA at Nafion/GC (d) and CNT-Nafion/GC (e) electrodes in $0.05 \mathrm{M}$ phosphate buffer at $\mathrm{pH} 7$ with a scan rate of $50 \mathrm{mV} / \mathrm{s}$. 
study is possibly due to the greater mass transport rate in the CNT-titania-Nafion composite film than in the CNT-Nafion composite film. In our previous work, the pore size $(3.14 \mathrm{~nm})$ of the titania-Nafion composite film determined from BET test was larger than that $(2.82 \mathrm{~nm})$ of pure Nafion film. ${ }^{22}$ In addition, the titania-Nafion composite film (pore volume $=0.28 \mathrm{~cm}^{3} \mathrm{~g}^{-1}$ ) was more porous than the pure Nafion film (pore volume $=$ $0.020 \mathrm{~cm}^{3} \mathrm{~g}^{-1}$ ). Therefore, the DA can easily diffuse into the CNT-titania-Nafion/GC electrode surface through the interconnected porous channels in the composite film.

Electrochemical impedance spectroscopic experiment has been carried out to probe the features of the composite-modified electrode surface. The diameter of the semicircle lying on the $\mathrm{Z}_{\mathrm{re}}$ corresponds to the charge transfer resistance $\left(R_{\mathrm{ct}}\right)$ of the redox probe ions, $\left[\mathrm{Fe}(\mathrm{CN})_{6}\right]^{3-} /^{4^{-}}$at the electrode interface. Figure 2 shows the Nyquist plots obtained at the different modified GC electrodes. The $R_{\mathrm{ct}}$ value measured at the Nafion-modified GC electrode was very high $(1671 \mathrm{k} \Omega)$ because of the repulsive interactions (electrostatic and steric) between the negatively charged redox probe ions, $\left[\mathrm{Fe}(\mathrm{CN})_{6}\right]^{3-} / 4^{--}$and the negatively charged Nafion-modified GC electrode surface. The repulsion impedes the charge-transfer through the interface. When the titania-Nafion composite is used instead of pure Nafion, the $R_{\text {ct }}$ value has almost halved $(878 \mathrm{k} \Omega$ ) because of the increased charge transport within the titania-Nafion composite film. When the CNTs were incorporated into the titania-Nafion composite, the $R_{\mathrm{ct}}$ value decreased dramatically to $151 \mathrm{k} \Omega$. This reflects that the conducting and electrocatalytic features of the CNTs facilitate the charge transfer between the probe and the electrode surface. Similar result was also reported in literature. ${ }^{27}$ However, when the CNTs were incorporated into the pure Nafion, the $R_{\mathrm{ct}}$ value increased significantly to $1302 \mathrm{k} \Omega$. This reflects again that the titania-Nafion composite is much more effective matrix than the pure Nafion for the construction of CNT-based electrochemical sensors because of the larger pore size and porosity.

Optimization of experimental conditions. The effect of operational potential on the amperometic detection of DA was studied over the potential range of $0.0-0.6 \mathrm{~V}$ with $0.05 \mathrm{mM} \mathrm{DA}$ in

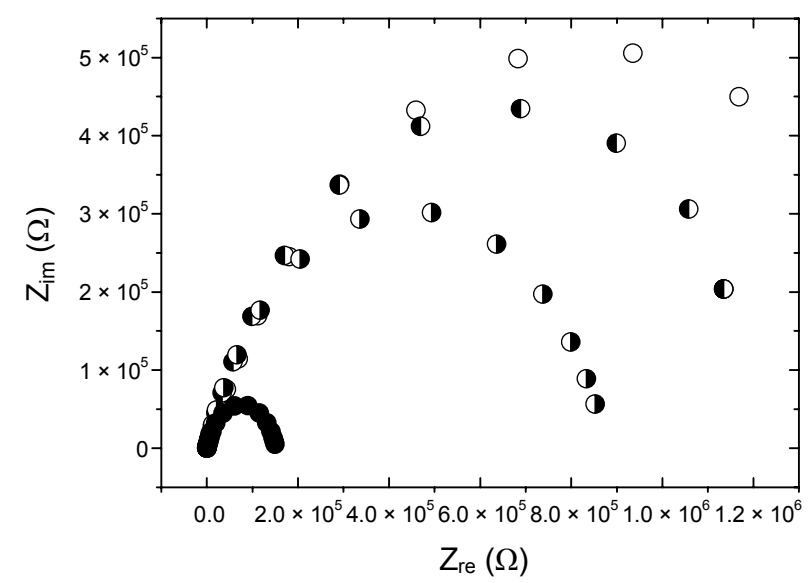

Figure 2. Nyquist plots of $5.0 \mathrm{mM} \mathrm{K}_{4} \mathrm{Fe}(\mathrm{CN})_{6} / \mathrm{K}_{3} \mathrm{Fe}(\mathrm{CN})_{6}$ solution in $0.05 \mathrm{M}$ phosphate buffer at Nafion/GC (०), CNT-Nafion/GC (○), titania-Nafion/GC (๑) and CNT-titania-Nafion/GC $(\bullet)$ electrodes.
$0.05 \mathrm{M}$ phosphate buffer at $\mathrm{pH}$ 7.0. As shown in Figure 3, the DA responses at the CNT-tiatania-Nafion/GC started at $0.2 \mathrm{~V}$ vs. $\mathrm{Ag} / \mathrm{AgCl}(3 \mathrm{M} \mathrm{NaCl})$, and then rapidly increased as the potential was positively changed from 0.2 to $0.35 \mathrm{~V}$. When the potential was further changed up to $0.4 \mathrm{~V}$, the response reached a plateau value. Although higher over-potential for the oxidation of DA results in higher response, a potential of $0.4 \mathrm{~V}$ was selected as an optimum potential for all subsequent amperometric experiments because the higher operational potential results in the increased interference from the oxidation of coexisting electroactive species such as AA and UA.

The effect of solution $\mathrm{pH}$ on the response of $0.01 \mathrm{mM}$ DA was investigated at the CNT-titania-Nafion/GC electrode over the $\mathrm{pH}$ range $4-10$. As shown in Figure 4, the anodic currents of DA were significantly small at alkaline solution $(\mathrm{pH} \geq 9.0)$ compared to those at other $\mathrm{pH}$ range tested $(4.0 \leq \mathrm{pH} \leq 8.0)$. Since the $\mathrm{p} K_{\mathrm{a}}$ of DA is $8.9, \mathrm{DA}$ is deprotonated at alkaline solution $(\mathrm{pH} \geq 9.0)$ and thus neutral DA is no longer electrostatically attracted into the negatively charged CNT-titania-Nafion composite film, which leads to the low amperometric response.

Response characteristics of CNT-titania-Nafion/GC elect-

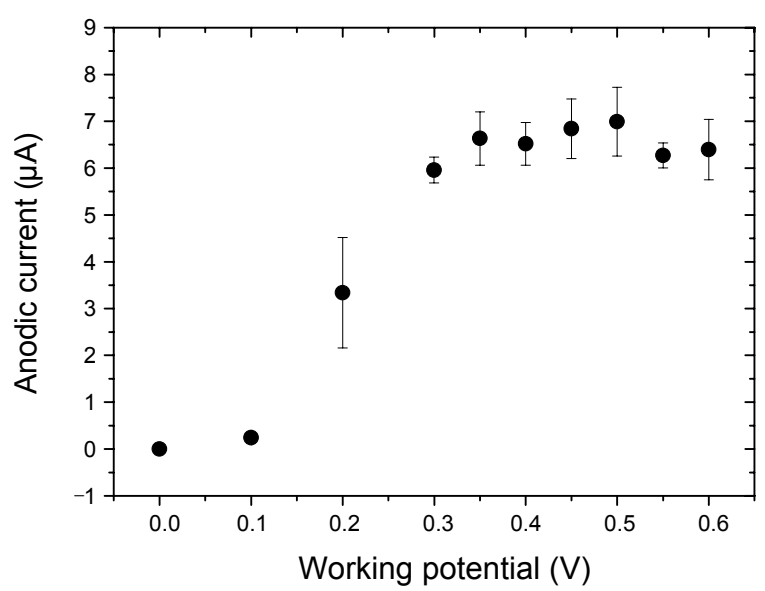

Figure 3. Effect of anodic current of $0.05 \mathrm{mM}$ DA on the working potential of the CNT-titania-Nafion/GC electrodes $(n=3)$.

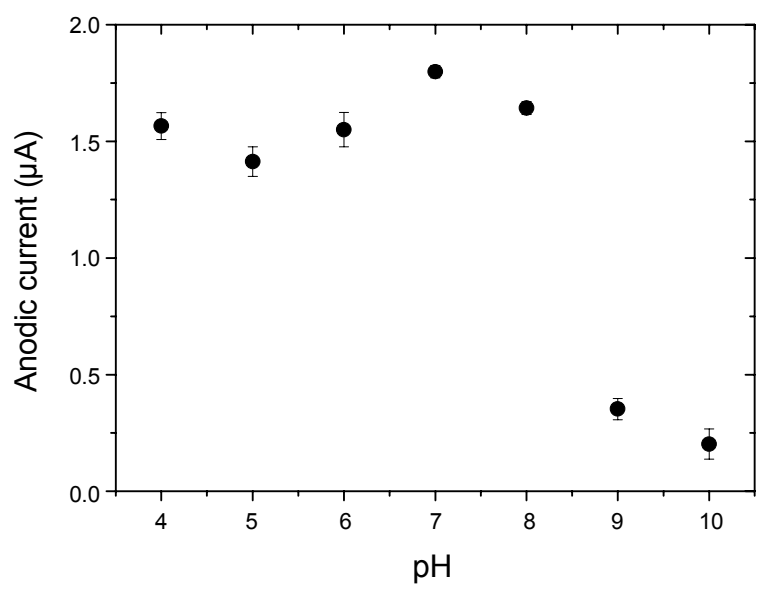

Figure 4. Effect of solution $\mathrm{pH}$ on the amperometric response of 0.01 $\mathrm{mM} \mathrm{DA}$ at the CNT-titania-Nafion/GC electrode at a potential of $0.4 \mathrm{~V}$. 
rode for DA. Using the optimum conditions obtained in the above studies, calibration curves of the DA sensor based on the CNT-titania-Nafion/GC electrode have been constructed by amperometry. As shown in Figure 5, the CNT-titania-Nafion/ $\mathrm{GC}$ electrode gave a linear response $\left(\mathrm{R}^{2}=0.999\right)$ for DA from $0.5 \mu \mathrm{M}$ to $500 \mu \mathrm{M}$ with a detection limit $(\mathrm{S} / \mathrm{N}=3)$ of $0.1 \mu \mathrm{M}$ and a good sensitivity of $150 \mathrm{~mA} / \mathrm{M}$ while other electrodes such as CNT-Nafion/GC, titania-Nafion/GC, and a bare GC gave a sensitivity of 89,39 , and $36 \mathrm{~mA} / \mathrm{M}$, respectively. The high sensitivity of the present DA sensor based on the CNT-titaniaNafion/GC electrode can be attributed to the porous nature of sol-gel titania-Nafion composite film as well as the electrocatalytic effect of CNT. As summarized in Table 1, the present DA sensor based on the CNT-titania-Nafion/GC electrode displayed a relatively low detection limit even without the additional loading of noble metal NPs such as $\mathrm{Pt}, \mathrm{Au}$ and $\mathrm{Pd}^{11-14}$ or

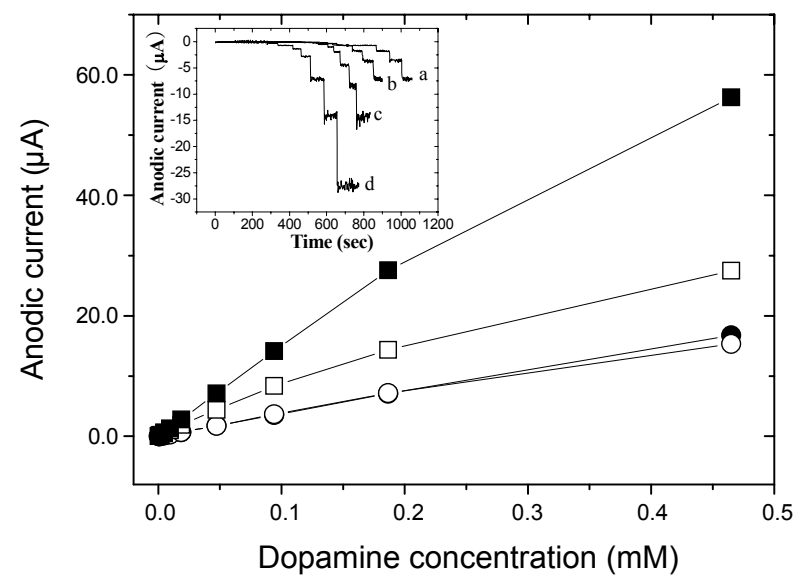

Figure 5. Calibration curves of DA at bare $\mathrm{GC}(\bullet)$, titania-Nafion/GC (०), CNT-Nafion/GC ( $\square$ ) and CNT-titania-Nafion/GC (ם) electrodes. Inset: typical current-time responses for $0.1 \mathrm{mM}$ DA obtained at bare GC (a), titania-Nafion/GC (b), CNT-Nafion/GC (c) and CNT-titaniaNafion/GC (d) electrodes.

Table 1. Performance comparison of the DA sensors based on different electrode materials

\begin{tabular}{|c|c|c|c|}
\hline Electrode material & Linear range & $\begin{array}{l}\text { Detection } \\
\text { limit }\end{array}$ & Reference \\
\hline $\mathrm{Au} / \mathrm{GC}$ & $15-135 \mu \mathrm{M}$ & $9.2 \mu \mathrm{M}$ & 11 \\
\hline $\mathrm{Pt} / \mathrm{Nafion} / \mathrm{GC}$ & $3.0-60 \mu \mathrm{M}$ & $0.01 \mu \mathrm{M}$ & 12 \\
\hline Nafion /PtAu/GC & $0.103-1.65 \mathrm{mM}$ & N. A. ${ }^{a}$ & 13 \\
\hline $\mathrm{Au} / \mathrm{PE} / \mathrm{PS} / \mathrm{BDD}^{b}$ & $5.0-100 \mu \mathrm{M}$ & $0.8 \mu \mathrm{M}$ & 14 \\
\hline $\mathrm{Pd} / \mathrm{CNF}^{-\mathrm{CPE}^{c}}$ & $0.5-160 \mu \mathrm{M}$ & $0.2 \mu \mathrm{M}$ & 15 \\
\hline GNS-Nafion/GC ${ }^{d}$ & $0.5-10 \mu \mathrm{M}$ & $0.02 \mu \mathrm{M}$ & 16 \\
\hline Graphene-Nafion/GC & $4-100 \mu \mathrm{M}$ & $2.64 \mu \mathrm{M}$ & 17 \\
\hline $\mathrm{C} 60-\mathrm{CNT} / \mathrm{GC}$ & $0.02-0.2 \mu \mathrm{M}$ & $0.03 \mu \mathrm{M}$ & 18 \\
\hline $\mathrm{Pt}-\mathrm{CNT} / \mathrm{GC}$ & $0.04-20 \mu \mathrm{M}$ & $0.03 \mu \mathrm{M}$ & 19 \\
\hline Nafion/Pt@Au/CNT/GC & Up to $120 \mu \mathrm{M}$ & $0.08 \mu \mathrm{M}$ & 20 \\
\hline $\mathrm{PU}-\mathrm{C} / \mathrm{Ni}(\mathrm{II}) / \mathrm{GC}^{e}$ & $0.25-30 \mu \mathrm{M}$ & $0.08 \mu \mathrm{M}$ & 21 \\
\hline CNT-titania-Nafion/GC & $0.5-500 \mu \mathrm{M}$ & $0.1 \mu \mathrm{M}$ & This study \\
\hline
\end{tabular}

${ }^{a}$ Not applicable, ${ }^{b}$ Gold NPs and polyelectrolytepolystyrene modified boron-doped diamond electrode, ${ }^{C} \mathrm{Pd}$ NPs-loaded carbon fibers modified carbon paste electrode, ${ }^{d}$ Graphite nanosheet-Nafion/GC, ${ }^{e}$ Polyurethane and electropolymerized $\mathrm{Ni}$ complex/GC. a complicated CNT modification step. ${ }^{18-20}$ However, the present sensor showed a relatively wide linear dynamic range from $0.5 \mu \mathrm{M}$ to $500 \mu \mathrm{M}$. Moreover, the present DA sensor based on the CNT-titania-Nafion/GC electrode exhibited relatively fast response time less than about $2.0 \mathrm{~s}$, which is much faster than those at the CNT-Nafion composite film (4.6 s) and titaniaNafion composite film (2.4 s) as shown in the current-time response profile (Figure 5, inset). It also results from the greater pore size of the titania-Nafion than pure Nafion and electrocatalytic effect of CNT.

Selectivity of CNT-titania-Nafion/GC electrode for dopamine detection. In order to verify the selectivity of the present CNT-titania-Nafion/GC electrode for DA detection, SWVs were obtained at the bare GC (Figure 6A) and the CNT-titaniaNafion/GC electrode (Figure 6B) for $0.5 \mathrm{mM} \mathrm{DA}$ (dashed line), $0.5 \mathrm{mM}$ AA (dot line) and a mixture of $0.5 \mathrm{mM} \mathrm{DA}$ and $0.5 \mathrm{mM}$

(A)

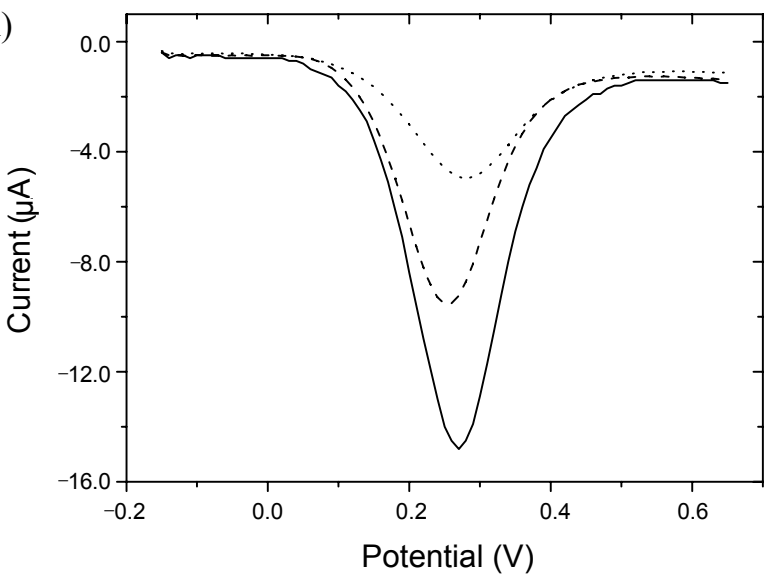

(B)

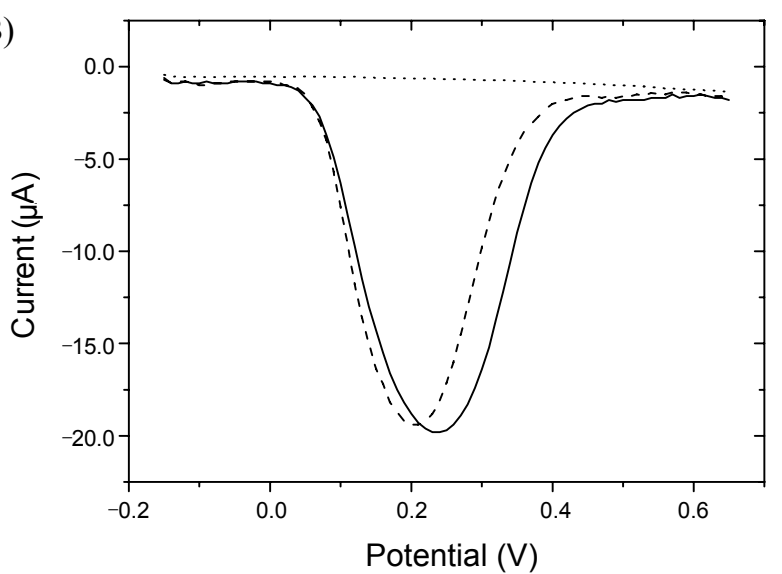

Figure 6. Square-wave voltammograms of $0.5 \mathrm{mM} \mathrm{DA}+0.5 \mathrm{mM}$ AA (solid line), $0.5 \mathrm{mMDA}$ (dashed line), and $0.5 \mathrm{mM} \mathrm{AA}$ (dot line) at bare GC (A) and CNT-titania-Nafion/GC (B) electrodes. Pulse height $=$ $25 \mathrm{mV}$, frequency $=20 \mathrm{~Hz}$, step height $=10 \mathrm{mV}$, scan rate $=100 \mathrm{mV} / \mathrm{s}$.

Table 2. Dopamine recovery tests in human urine and serum samples

\begin{tabular}{cccc}
\hline Sample & $\begin{array}{c}\text { Added dopamine } \\
\text { concentration }(\mu \mathrm{M})\end{array}$ & $\begin{array}{c}\text { Obtained dopamine } \\
\text { concentration }(\mu \mathrm{M})\end{array}$ & $\begin{array}{c}\text { Recovery \% } \\
( \pm \mathrm{SD})\end{array}$ \\
\hline Urine $^{a}$ & 10.0 & 10.07 & $100.2 \pm 5.8$ \\
Serum $^{b}$ & 10.0 & 9.66 & $96.6 \pm 0.47$
\end{tabular}

${ }^{a} 1000$ times dilution with PBS. ${ }^{b} 200$ times dilution with PBS. 
AA (solid line). As can be seen in Figure 6A, the anodic peak potentials of DA $\left(E_{p a}=0.25 \mathrm{~V}\right)$ and $A A\left(E_{p a}=0.28 \mathrm{~V}\right)$ at the bare $\mathrm{GC}$ electrode were very close to each other and were almost indistinguishable. Thus, the mixture of DA and AA produced a single voltammetric peak at $0.27 \mathrm{~V}$, which is a major problem for electrochemical detection of DA in real biological samples. In contrast, the DA anodic current obtained at the CNT-titaniaNafion/GC electrode was about twice larger than that at the bare GC electrode as shown in Figure 6B, while the AA anodic current was almost negligible because the negatively charged CNTtitania-Nafion composite film repels the negatively charged ascorbate anion and thus allows positively charged DA alone to reach the electrode surface. In addition, the anodic current of the mixture of $0.5 \mathrm{mM}$ DA and $0.5 \mathrm{mM}$ AA obtained at the CNT-titania-Nafion/GC electrode were only $1.7 \%$ larger than that of only $0.5 \mathrm{mM}$ DA in the absence of AA. Like the AA, UA also had no interference effect at the CNT-titania-Nafion/ GC electrode (data are not shown). The result indicates that the presence of Nafion in the CNT-titania-Nafion composite film greatly diminishes the interferences from AA and UA.

The recovery of DA in spiked human urine and serum samples were examined by SWV. The urine and serum samples were 1000-fold and 200-fold, respectively, diluted with $0.05 \mathrm{M}$ phosphate buffer and SWVs were obtained at the CNT-titaniaNafion/GC electrode. The results are listed in Table 2. For the five independent measurements, the recovery of urine sample was $100.2 \%$ with $5.8 \%$ standard deviation, while the recovery of serum sample was $96.6 \%$ with $0.47 \%$ standard deviation. This indicates that the CNT-titania-Nafion/GC electrode has high selectivity for DA and can be used even in a biological sample where the large amount of AA and UA are present.

\section{Conclusions}

The CNT-titania-Nafion composite film modified GC electrode has been used for a highly sensitive and selective electrochemical determination of DA in human urine and serum samples. Due to the large pore size of the composite film of solgel-derived titania-Nafion film, the present DA sensor based on the CNT-titania-Nafion/GC electrode the exhibited very fast response time less than $2 \mathrm{~s}$. In addition to the large pore size, the incorporation of CNT within the titania-Nafion composite films increased the DA response because of the electrocatalytic activity of CNT towards DA and the decreased charge transfer resistance in the composite-modified GC electrode. Thus, the present DA sensor based on the CNT-titania-Nafion/GC electrode displayed a reasonably good sensitivity along with a detection limit $(\mathrm{S} / \mathrm{N}=3)$ of $0.1 \mu \mathrm{M}$ without a complicated $\mathrm{CNT}$ modification step or the additional loading of noble metal NPs such as Pt, Au, and Pd. Moreover, the present DA sensor almost completely eliminated the interference from AA and UA in the biological samples without an additional Nafion film coating process on the DA sensor commonly employed in other DA sensors. The sensitivity of the present DA sensor along with its good selectivity and reproducibility might allow us for its potential use in the diagnosis of DA-related diseases.

Acknowledgments. This work was financially supported by the Korea Science and Engineering Foundation through the Center for Bioactive Molecular Hybrids (CBMH). B. K. Kim and H. N. Choi acknowledge the fellowship of the BK 21 program from the Ministry of Education and Human Resources Development.

\section{References}

1. Damir, P.; Hirsch, E. C.; Graybiel, Y. A. M. Brain. 1999, 122, 1473.

2. Doménech, A.; García, H.; Doménech-Carbó, M. T.; Galletero, M. S. Anal. Chem. 2002, 74, 562.

3. Zhao, Y.; Gao, Y.; Zhan, D.; Liu, H.; Zhao, Q.; Kou, Y.; Shao, Y.; Li, M.; Zhuang, Q.; Zhu, Z. Talanta 2005, 66, 51.

4. Zhang, M.; Gong, K.; Zhang, H.; Mao, L. Biosens. Bioelectron. 2005, 20, 1270.

5. Lin, X.; Gong, J. Anal. Chim. Acta 2004, 507, 255.

6. Kawagoe, T. K.; Wightman, R. M. Talanta 1994, 31, 865.

7. Xu, F.; Gao, M.; Wang, L.; Shi, G.; Zhang, W.; Jin, L.; Jin, J. Talanta 2001, 55, 329.

8. Fragoso, A.; Almirall, E.; Cao, R.; Echegoyen, L.; Gonzalez-Jonte, R. Chem. Commun. 2004, 2230.

9. Jiang, X.; Lin, X. Analyst 2005, 130, 391.

10. Britto, P.; Santhanam, K.; Ajayan, P. Bioelectrochem. Bioenerg. 1996, 41, 121.

11. Zhang, L.; Jiang, X. J. Elecrtoanal. Chem. 2005, 583, 292.

12. Selvaraju, T.; Ramaraj, R. J. Elecrtoanal. Chem. 2005, 585, 290.

13. Thiagarajan, S.; Chen, S.-M. Talanta 2007, 74, 212.

14. Wei, M.; Sun, L. G.; Xie, Z. Y.; Zhii, J. F.; Fujishima, A.; Einaga, Y.; Fu, D. G.; Wang, X. M.; Gu, Z. Z. Adv. Funct. Mater. 2008, 18, 1414.

15. Huang, J.; Liu, Y.; Hou, H.; You, T. Biosens. Bioelectron. 2008, 24, 632 .

16. Chen, S.; Yang, W.; Chen, X. Electroanlysis 2010, 22, 908.

17. Kim, Y.-R.; Bong, S.; Kang, Y. -J.; Yang, Y.; Mahajan, R. K.; Kim, J. S.; Kim, H. Biosens. Bioelectron. 2010, 25, 2366.

18. Zhu, H.; Wu, W.; Zhang, H.; Fan, L.; Yang, S. Electroanlysis 2009 , $21,2660$.

19. Dursun, Z.; Gelmez, B. Electroanlysis 2010, 22, 1106.

20. Bai, Y.-C.; Zhang, W.-D. Electroanlysis 2010, 22, 237.

21. Xu, G.-R.; Zhang, Y. P.; Tao, J. Z.; Kim, S.; Bae, Z.-U. Electroanlysis 2007, 19, 1085.

22. Choi, H. N.; Cho, S.-H.; Lee, W.-Y. Anal. Chem. 2003, 75, 4250.

23. Choi, H. N.; Lee, J.-Y.; Lyu, Y.-K.; Lee, W.-Y. Anal. Chim. Acta 2006, 565,48 .

24. Lee, Y.-J.; Lyu, Y.-K.; Choi, H. N.; Lee, W.-Y. Electroanlysis 2007, 19, 1048.

25. Choi, H. N.; Lyu, Y.-K.; Han, J. H.; Lee, W.-Y. Electroanlysis 2007, 19, 1524.

26. Choi, H. N.; Han, J. H.; Park, J. A.; Lee, J. M.; Lee, W.-Y. Electroanlysis 2007, 19, 1757.

27. Yoon, S. H.; Han, J. H.; Kim, B. K.; Choi, H. N.; Lee, W.-Y. Electroanlysis 2010, 22, 1349. 